\title{
Memorias intimas y espacio social: el pueblo de Peyruis (Francia) a mediados del siglo $X X^{1}$
}

\author{
Intimate memories and social space: the village of peyruis \\ (France) in the middle of $X X^{\text {th }}$ century
}

\author{
Alain Musset \\ Escuela de Altos Estudios en Ciencias Sociales de París \\ musset@ehess.fr (FRANCIA)
}

Recibido: 21.102012

Aceptado: 31.10 .2013

\section{RESUMEN}

Los lugares destacados juegan un papel fundamental en la organización simbólica del territorio y en su puesta en conformidad con la historia oficial. Son la expresión de una identidad colectiva que se expresa a diferentes niveles tanto sociológicos como políticos, desde la nación hasta la familia (escala de análisis hasta entonces poco estudiada). Con el propósito de ver cómo el espacio-tiempo de los individuos se articula con el espacio-tiempo de la sociedad, he emprendido una investigación cuyo tema y objeto es mi propia familia y su cuna lugareña, Peyruis (Francia, antiguo departamento de los Alpes Bajos). Al reconstruir la geografía íntima de tres hermanas y su hermano en este pueblo provenzal de los años 1940, pasamos de los lugares institucionales de la memoria a una memoria de los lugares comunes y corrientes, lugares de la trivialidad no relacionados con el culto periódico de los recuerdos oficiales sino con las practicas diarias de la sociedad. De hecho, esos pequeños lugares destacados se ubican en un espacio social más amplio y expresan la apropiación virtual (y limitada en el tiempo) de un territorio público por una memoria privada.

\section{PALABRAS CLAVES}

Peyruis, lugares destacados, territorio, familia, intimidad.

1 Una versión anterior de este texto ha sido previamente publicada en la revista Cahiers de Géographie du Québec, volume 52, numéro 145, avril 2008, p. 63-79. 


\begin{abstract}
The memorable places (landmarks) have a fundamental place in the symbolic marking of territory and in its connexion with official history. They express a collective identity which is shown at different political and sociological levels, from the nation down to the family- a scale of analysis hitherto neglected. To see how individuals' space-time mesh with that of society, I began to research my own family and its birthplace - Peyruis, Alpes de Haute-Provence in France. By reconstructing the private geography of three sisters and a brother in this small, 1940's Provenzal town, we move from institutional memorials to commonplace ones : everyday places more linked to daily activities than regular acts of remembrance. These small significant sites are found in a social space. They embody virtual and limited in time appropriation of a public territory by a private memory.
\end{abstract}

\title{
KEYWORDS
}

Peyruis, memorable places, territory, family, intimacy.

\section{INTRODUCCIÓN}

En Francia, desde los trabajos pioneros de Pierre Nora, los lugares de memoria ocupan un lugar fundamental en la demarcación simbólica del territorio y en su relación con la historia oficial. Son la expresión de una identidad colectiva que se manifiesta a distintos niveles sociológicos o políticos. Sin embargo, como lo recuerda Giovanni Lévi, el concepto mismo de memoria sufrió durante los últimos 30 años una pérdida de sentido conforme se fragmentaban los discursos históricos: «El proceso triunfal de la individualización, de la privatización de la experiencia, produjo una memoria fragmentada, individualizada. Es la memoria de cada uno, no la de un grupo, o de un pueblo, que entra continuamente en escena» (Lévi, 2001: 31-32).

Consecuencia directa de esta abundancia de memorias y relatos que no solamente ya no se funden en el molde de una identidad colectiva sino que pretenden al contrario apartarse y distinguirse de dicha identidad colectiva, se multiplican los lugares encargados de conservar la huella de grupos cuya definición es cada vez más estricta y cuyas dimensiones son cada vez más reducidas. Como le decía al respecto Mauricio Halbwachs: «Cada aspecto, cada detalle de este lugar tiene un sentido que sólo es inteligible para los miembros del grupo, porque todas las partes del espacio que ocupó dicho grupo corresponde a tantos aspectos diferentes de la estructura y de la vida de su sociedad» (Halbwachs, 1967: 99).

Pero en este conjunto de trabajos sobre los lugares, la historia y la memoria, una dimensión fundamental queda hasta ahora descuidada y a menudo menos- 
preciada porque se ubica en la trivialidad de la vida cotidiana y en el carácter efímero de los recuerdos personales: quiero hablar de las memorias familiares e individuales. Es así como Michel Lussault pudo distinguir dos categorías de lugares dotados de fuerte carga social y de valores comunes: por una parte los «lugares destacados» tal como la calle, la plaza publica, o el monumento «lugar de memoria» que permiten la condensación social de una memoria colectiva. Por otra parte, encontramos los «lugares domésticos» (departamentos, casas, cuartos, jardines...) que pertenecen a la esfera privada de los actores sociales y que, por consiguiente, constituyen un conjunto espacial más ordinario (Di Méo, 2001: 47). Sería sin embargo una equivocación creer que existe una frontera impermeable entre los lugares de la memoria colectiva (aquélla que pretende dar un sentido al grupo) y los de esas memorias individuales supuestamente recogidas en si mismas: ambas geografías se superponen, coinciden, se cruzan continuamente y se nutren una de otra - tal como lo han demostrado de manera muy clara los investigadores anglosajones que, recientemente, se han dedicado a la llamada «geografía emocional» y no dudaron en hablar de un «emocional turn» para destacar la importancia de esas emociones tanto individuales como colectivas que dan sentido a los territorios de la cotidianeidad (Davidson, Bondi y Smith, 2007).

En 2008, con el fin de entender mejor cómo se articulan entre sí estos distintos espacios, emprendí trabajar en los «pequeños lugares de memoria» de una familia - la mía, cuya cuna se sitúa en Peyruis, pequeña ciudad que cuenta hoy día un poco más de dos mil habitantes (menos de mil en los años cuarenta) situado en el sur de Francia. Si bien se trata de un planteamiento inusual y poco ortodoxo en un mundo científico en busca permanente de objetividad, no dudaré en tomar aquí el «partido por mis lugares», para usar la expresión de Martin de La Soudière (1991: 20). Aún más, quiero destacar la legitimad del «yo» en la investigación geográfica y en el trabajo de campo, tal como lo plantearon de manera a veces polémica los autores del numero especial de la revista Annales de Géographie titulado «Terrains de je. (Du) sujet (au) géographique» (Volvey, Calbérac, Houssay-Holzschuch, 2012) ${ }^{2}$. En efecto, en el dicho pueblo de Peyruis mi madre $\left(\right.$ Monique $^{3}$ ), sus dos hermanas $\left(\right.$ Josette $^{4}$ y Mireille ${ }^{5}$ y su hermano $\left(\operatorname{Jean}^{6}\right)$ pasaron toda su juventud antes de casarse y dispersarse.

2 La introducción de este número especial es accesible en Internet: Anne Volvey, Yann Calbérac y Myriam Houssay-Holzschuch «Fielding the (geographical) subject», http://www.cairn.info/ revue-annales-de-geographie-2012-5-page-441a.htm.

3 Monique Vernet, nacida en Marsella en 1930, llegó a Peyruis con su familia en 1939. Se casó con Richard Musset en 1946 y se radicó en Saint-Auban. De 1955 à 1958 la pareja residió en Ribécourt (norte de Francia), y luego se asentó en Lavéra (cerca de Marsella) antes de comprar un departamento en Martigues (1966). Falleció el primero de octubre de 2008.

4 Josette Vernet nació en Marsella en 1929. Vivió durante dos años (1942-1944) en una casarefugio para niños de Lucinges (Alpes). Dejó definitivamente su pueblo en 1946. Casada en 1952 con Robert Mercier, vive en Pélussin (cerca de Lyon) desde 1958.

5 Mireille Vernet, nacida en Digne en 1938, vivió en Peyruis hasta 1947 y luego en SaintAuban. Casada, volvió a vivir en su pueblo en 1969 hasta su divorcio en 1979.

6 Jean Vernet, nacido en Marsella en 1934, vivió en Peyruis hasta fines de 1947, cuando su 
Este tipo de microinvestigación a escala de un núcleo familiar y llevada a cabo en un espacio de tiempo limitado (un verano) ${ }^{7}$ permite hacer el enlace entre el espacio-tiempo de los individuos y el espacio-tiempo de la sociedad ya que, al fin y al cabo, ningún lugar se sitúa fuera del tiempo social: sólo el grado de integración (o la intensidad de la conexión) varía entre la publicidad objetiva de los lugares y la intimidad real o supuesta de los momentos que los individuos, considerados como actores de su propia vida, pasaron en este escenario público.

\section{LOS LUGARES, EL RECUERDO Y EL OLVIDO: UN PROBLEMA METODOLÓGICO}

Al trabajar a otra escala que la de los Estados, de las naciones o las comunidades de cualquier forma y de cualquier tamaño, es posible ver cómo la memoria de una familia se relaciona o no con la historia oficial, cómo se nutre de ella y cómo la mantiene. Se muestra también cómo los territorios individuales suelen articularse con los espacios sociales. Pasamos entonces de los lugares de memoria institucionales a la memoria de los lugares comunes y corrientes - esos lugares vinculados a las prácticas diarias y no al culto periódico del recuerdo. De hecho, el tiempo individual y el tiempo social están conectados entre sí por medio de ciertos puntos de referencia que dan ritmo a la vida de los grupos (en el sentido más amplio de la palabra) y la de las familias. En esta perspectiva, el recuerdo de los lugares caracterizados por el «yo» (lo intimo), el «aquí» («aquí ocurrió... ») y lo transitorio (una vida humana) permite poner en escena una geografía fugaz pero esencial porque, como lo decía F. Braudel, se inscribe en «una historia aún caliente, tal como los contemporáneos la sintieron, la describieron, la vivieron, al ritmo de su vida, breve como la nuestra» (Braudel, 1990: 17).

Al encarnar un momento preciso (o una duración más o menos larga) en la historia de un individuo y de su familia, estos lugares son realmente «destacados». Materializan la apropiación virtual (y limitada en el tiempo) de un territorio público por una memoria privada - siguiendo en eso el esquema general propuesto por la psychogeografía de Abraham Moles: «Es la idea que este lugar particular es caracterizado por mi presencia, por mis actos, por mis objetos o

familia se mudó hacia Saint-Auban. Luego de cinco años pasado en la armada francesa, se casó en 1956 y vive desde aquel entonces cerca de la ciudad de Sisteron.

7 Dicha investigación se realizó durante el mes de agosto de 2008, aprovechando una reunión de todos los ancianos de la familia en el sur de Francia. Las entrevistas (sin cuestionario preestablecido) se hicieron de manera individual pero diálogos entre los protagonistas pudieron desarrollarse cuando se presentaba la oportunidad. Conversaciones telefónicas posteriores permitieron aclarar unos puntos que necesitaban ser profundizados. Los discursos no han sido grabados sino transcritos manualmente. Solo dos personas, Jean y Richard, aceptaron dibujar el mapa mental de sus territorios. Las tres hermanas me expresaron que no tenían la capacidad técnica de hacerlo. Esta experiencia, al nivel médico y psicológico, ha sido también una manera devolverles más agilidad intelectual a las dos personas mas vulnerables, Richard y Monique. 
los seres que yo ubiqué allí, que lo vuelve a mis ojos distinto de cualquier otro lugar» (Moles, 1995: 173). Es, por ejemplo, el caso de la geografía del primer beso. Si bien se trata de un acto íntimo por excelencia, se inscribe en lógicas espaciales de grupos. En efecto, como lo veremos más adelante, según su origen social o étnico, su nivel de educación, su lugar de residencia, su preferencia sexual (entre otros numerosos parámetros), los protagonistas de este rito iniciático cuyo recuerdo es tradicionalmente calificado de inolvidable eligen un escenario a la altura de sus esperas, al alcance de su imaginario - cuando no es el propio escenario que los elige.

En la misma perspectiva, cabe resaltar que los lugares no tienen el mismo sentido ni el mismo valor según la edad y el sexo del observador, ${ }^{8}$ según su grado de integración a la vida y a las actividades de un grupo social en particular, o según el tiempo que pasó en un lugar determinado. En el proceso de reconstrucción de la memoria, es necesario tener en cuenta los múltiples rodeos o enfoques que afectan y orientan la manera de percibir y representar tanto los acontecimientos, como su marco geográfico y su integración a un relato. En todos los sentidos del término, se trata de una puesta en escena consciente o inconsciente que yuxtapone recuerdos personales, relatos familiares y memoria colectiva.

Con todo, el pueblo de Peyruis nunca ha sido el escenario de eventos mayores en la historia de la Nación francesa, así que no cuenta con esos grandes lugares de memoria identificados por Pierre Nora para dar sentido a un proyecto comunitario. De manera paradójica, el único acontecimiento de alcance nacional cuyo escenario ha sido Peyruis es hoy en día ocultado por las autoridades locales, a pesar de seguir presente en las memorias familiares y en el imaginario colectivo de gran parte de los Franceses: se trata del caso Dominici.

En efecto, en la noche del 4 al 5 de agosto de 1952, tres ingleses, Jack Drummond, su mujer Ann y su hija Isabel han sido asesinatos de manera escalofriante cerca de una finca situada a poco menos de 8 kilómetros de Peyruis. Este acontecimiento sangriento tuvo Francia en vilo durante varios años y sigue nutriendo crónicas judiciales y foros de debates donde se oponen partidarios y adversarios del «patriarca» Gastón Dominici, condenado a muerte para este triple asesinato antes de ver su pena conmutada en cadena perpetua (14 de julio de 1957) y en adelante de obtener su liberación debido a su edad avanzada (13 de julio de 1960). En 1973, el gran actor Jean Gabin interpretó el papel de este personaje controvertido en una película cuyo realizador, Claude Aubert, hacía hincapié en las fallas de la investigación llevada a cabo por la policía. Más recientemente, en 2003, otra película tomó abiertamente partido por la tesis del error judicial.

Ahora bien, para entender la relación establecida en el transcurso del tiempo entre una sociedad y su territorio, no basta estudiar los famosos lugares de

8 Como lo decía al respecto mi tío Jean : «al contrario de mis hermanas, yo quedaba libre de organizar a mi gusto mi pequeña vida exterior». 
memoria que son el garante de un patrimonio histórico común y reconocido de todos: es importante investigar también los lugares del olvido que, como lo demostraron Halbwachs (1950) o Augé (1998), desempeña un papel esencial (pero más discreto) en la construcción de las identidades colectivas. Tal como lo decía el filósofo Paul Ricoeur: «El olvido puede ser mezclado a la memoria de manera tan estrecha que podemos considerarlo como una de sus condiciones» (Ricoeur, 2000: 553).

Al seguir el pensamiento de Halbwachs, es preciso decir que si bien una parte de este olvido puede ser la consecuencia del silencio y del rechazo, otra parte corresponde a la simple desaparición de los protagonistas de la memoria: «La memoria de una sociedad se extiende hasta donde puede, es decir, hasta dónde alcanza la memoria de los grupos que la conforman. No es por mala voluntad, antipatía, repulsión o indiferencia que dicha sociedad olvida tantos acontecimientos y tantas figuras antiguas. Es que los grupos que guardaban su recuerdo desaparecieron» (Halbwachs, 1967: 47). Por supuesto, esta memoria es tanto más frágil cuanto que los grupos involucrados en dicho proceso son reducidos (caso de una familia nuclear) y que la memoria se transmite por tradición oral.

Sin embargo, en las memorias familiares de Peyruis, el caso Dominici no ha sido completamente borrado o artificialmente mantenido por el cine y la televisión. Los ancianos todavía se acuerdan no sólo de los lugares del drama sino también de los protagonistas quienes conocieron personalmente. Más de medio siglo después del acontecimiento, Mireille, la hermana menor de la familia, lograba perfectamente insertarlo en su historia personal (tenía 14 años en 1952): «Oía hablar del caso Dominici. Volvía de vacaciones. Este mismo día había ocurrido el asesinato, todo el mundo hablaba de esto y decía cómo había pasado. La finca, la ví después, cuando fuimos a ver el pequeño puente. Se decía: allí mataron a los Drummond. Recuerdo muy bien el pequeño puente, el camino. Durante años, al pasar por allí solíamos decir: oye, aquí es la finca donde asesinaron a los Drummond».

Monique también me dijo que, durante la guerra, su padre trabajaba como jornalero en la finca de Gastón Dominici, el cual lo pagaba con frutos y verduras. Ahora bien, este recuerdo personal de poca importancia sólo vale por su integración a una historia compartida en su tiempo por la mayoría de los franceses. Para ubicar su vida anónima en el marco de un acontecimiento de alcance nacional cuyos participantes volvieron a ser personajes de película, padres y abuelos no dudaron en compartir su experiencia íntima de los lugares con sus niños y nietos. Recuerdo que, cuando yo tenía ocho o diez años (es decir a fines de los años 60) a veces íbamos a visitar a mi tía Mireille y a mi abuela que ambas vivían todavía en Peyruis. Mis padres siempre me mostraban la finca cerca de la cual encontraron los tres cadáveres, el 5 de agosto de 1952. A decir la verdad, esta casa fea y solitaria solía espantarme (figura 1). 
Figura 1. La finca Dominici, cerca de Peyruis (fotografía: Alain Musset, 2008)

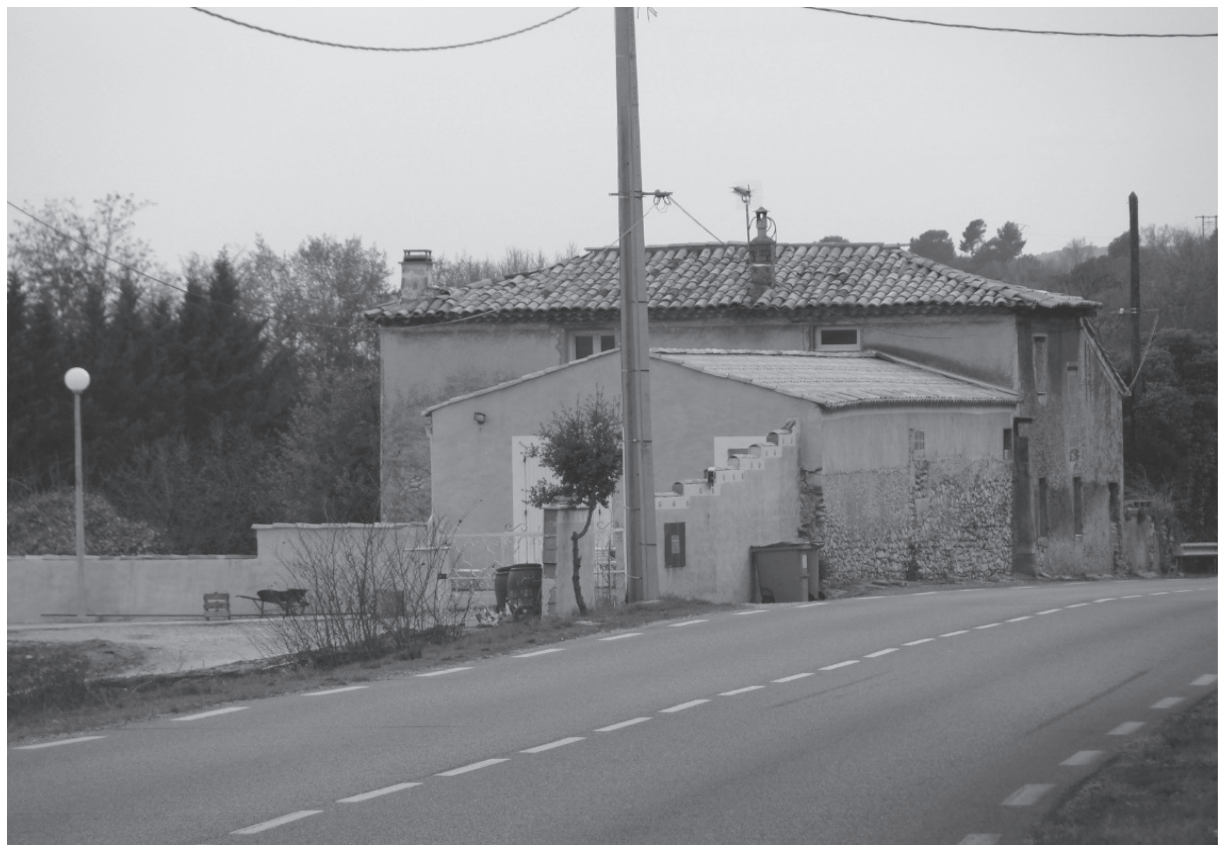

La importancia del juicio y su tratamiento mediático permitieron a mis padres mantener la memoria de un conjunto de lugares a priori sin importancia cuyo valor sólo se basa en la relación establecida a posteriori entre los territorios de su vida cotidiana y el carácter excepcional del acontecimiento. De allí que se dibuja una geografía bastante ambigua donde los «lugares destacados» no son sino los mismos «lugares domésticos» que pertenecen a la supuesta «esfera privada de los actores sociales» y donde los recuerdos personales se mezclan con la memoria colectiva. En este conjunto encontramos no sólo la finca de la Grand Terre donde ocurrió el crimen, sino también la casa de uno de los hijos del patriarca (ubicada en Peyruis cerca de la panadería donde mi mama solía comprar el pan), la finca de la hija de Gastón Dominici donde mi abuela iba a comprar su leche, y varios otros lugares que pertenecen, directa o indirectamente, al mismo ámbito histórico. Aún más, en el sitio mismo del asesinato, si bien ninguna lápida conmemorativa recuerda la crueldad de los hechos (porque las autoridades escogieron el camino del olvido), quedan pruebas de que su memoria no ha sido completamente borrada: 56 años después del drama, un ramo de flores artificiales adornado de muñecas y muñecos de peluche sigue señalando el lugar donde ha sido encontrado el cuerpo martirizado de la pequeña Isabel, después del puente de piedra que cruza la vía de ferrocarril (figura 2). 
Figura 2. Ramo de flores y peluches en memoria de la joven Isabel (fotografia: Alain Musset, 2008)

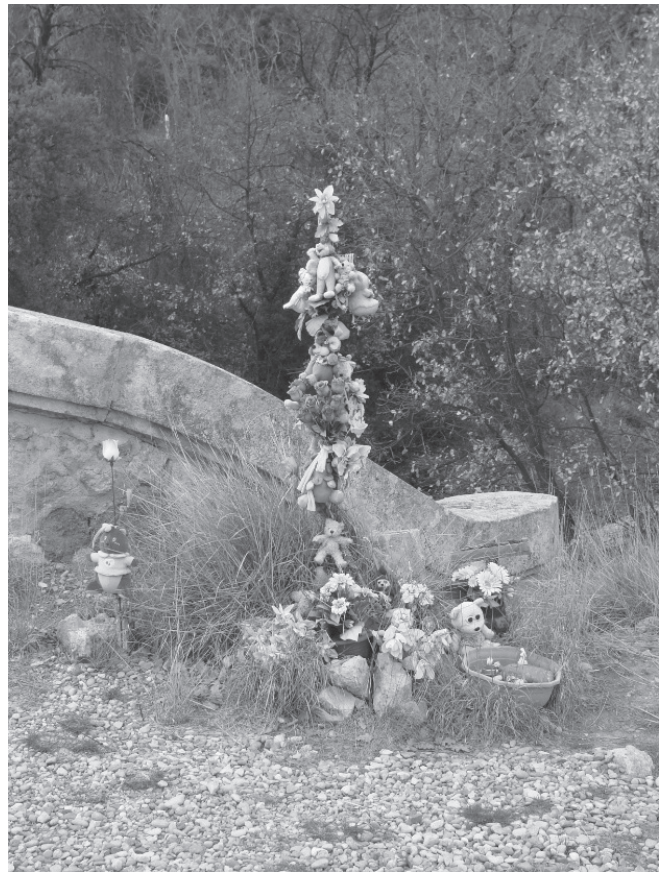

\section{PEYRUIS O LOS «POBRES LUGARES» ${ }^{9}$ DE UNA PEQUEÑA CIUDAD}

Pero, a parte de no tener historia, ¿será que Peyruis tampoco tenga lugares destacados? Cuando se le preguntaba cuales eran los lugares más importantes de su pueblo, Monique solía decir que «no hay nada que ver en Peyruis». Esta afirmación es confirmada por Josette, para quien «la vuelta de Peyruis se hacía rápidamente». Sin embargo, este «no hay nada que ver» era inmediatamente ponderado por una referencia al castillo en ruinas que domina la carretera de Sisteron y el valle del río Durance. Para Josette, esta antigua fortaleza medieval era sobre todo el lugar donde, cada domingo, las muchachas de la parroquia solían pasear: «era un momento de libertad, allí nuestros corazones se abrían. Allí se respiraba un poco. Antes de ir a las vísperas, solíamos subir al castillo». Su hermana Mireille era más joven, así que un lugar tan peligroso le quedaba prohibido. Es sin embargo el primer lugar que le viene a la mente cuando se le hace la pregunta: «Me acuerdo de las ruinas. Me

9 Según la tradición, las tres $\mathrm{P}$ que acompañan el escudo de la ciudad significan: Peyruis Pobre Pueblo. 
decían que era el antiguo castillo de un señor pero no me dejaban acercar. Fui allí una sola vez, pero eso me impactó». Al gozar de más libertad por ser el único varón de la familia, mi tío Jean pasaba mucho tiempo en este monumento en ruinas, buscando tesoros imaginarios : «En 1940, las ruinas del castillo seguían imponentes, con numerosos y altos muros de piedra... Cuantas veces hemos penetrado en esos vestigios ancestrales? ...Dejando a nuestra imaginación infantil el gusto de reinventar la sala de armas, los departamentos, la capilla, la torre del homenaje» (figura 3).

Figura 3. Ruinas del castillo de Peyruis (fotografía : Alain Musset, 2010)

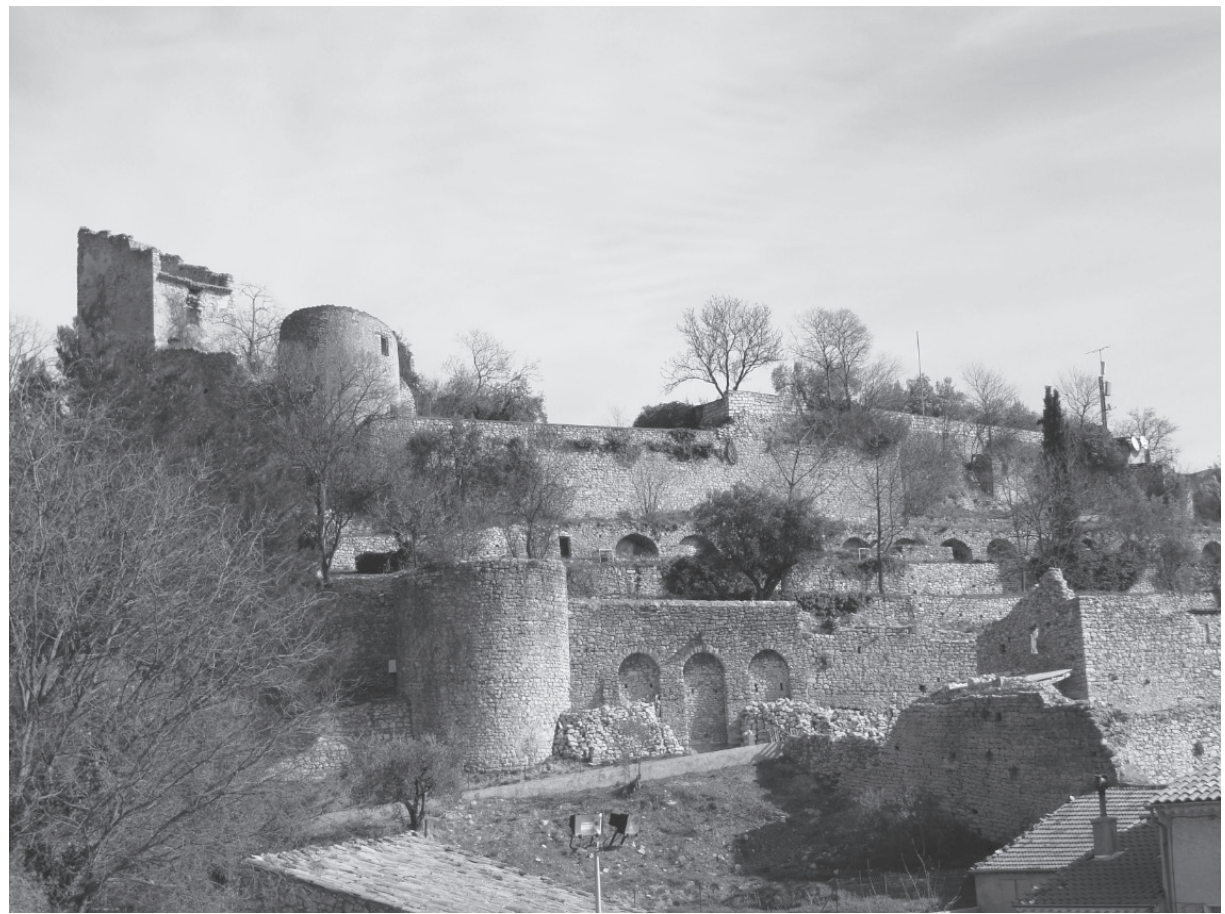

Con el tiempo, la percepción del patrimonio arquitectónico suele cambiar porque, como lo destaca Josette, las personas mayores saben ver y reconocer los verdaderos tesoros que, en su juventud, ignoraban por falta de cultura y educación: «Hay una puerta muy bonita en Peyruis, subiendo a la iglesia. Hay escudos de armas. Es una especie de bóveda, en frente de una fuente. Cuando era niña, yo pasaba abajo, pero no me daba cuenta de su importancia». Al hacer hincapié en un patrimonio de proximidad representativo de cierta identidad local, la asociación «Vivir en Peyruis» intentó devolver todo su valor histórico y cultural a los pequeños lugares destacados del pueblo (Mouïren, 1997: 119). El catálogo final es sin embargo bastante corto ya que sólo pretende distinguir elementos dados por excepcionales: la capilla santo Roch, el albergue del Gran Cabaret, las casas «nobles» (gentilhommières), la puerta de la calle de la judería, las fuentes, el horno comunal, la iglesia y el castillo. 
Prueba del desfase que existe entre este patrimonio «oficial» y las memorias familiares, dicha lista sólo corresponde parcialmente a los lugares que los ancianos de la familia Vernet recuerdan porque formaban parte de su vida diaria - tal como lo demuestra el mapa de Peyruis dibujado por mi tío Jean (figura 4). Este documento de gran calidad gráfica valoriza los lugares que tienen sentido para su autor y que podemos dividir en varias categorías: los espacios públicos (calles, avenidas, Plaza de la iglesia, Plaza Parlatan, Plaza de los sicomoros (platanes en francés), Plaza de la Fuente; el patrimonio monumental (ruinas el castillo, capilla Santo Roch, albergue del gran Cabaret, fuente Parlatan, puerta de la calle de la judería, iglesia, monumento a los caídos); los lugares de sociabilidad (Café de France, Café de los Alpes); los espacios familiares (Maison Fié y antigua Hostelería del Parque, lugares de residencia de la familia Vernet en Peyruis). La salida meridional del pueblo («hacia Marsella») se caracteriza por la presencia del cementerio comunal, importante lugar de sociabilidad para los miembros de la comunidad.

Figura 4. Mapa del pueblo de Peyruis dibujado por Jean Vernet (2009)

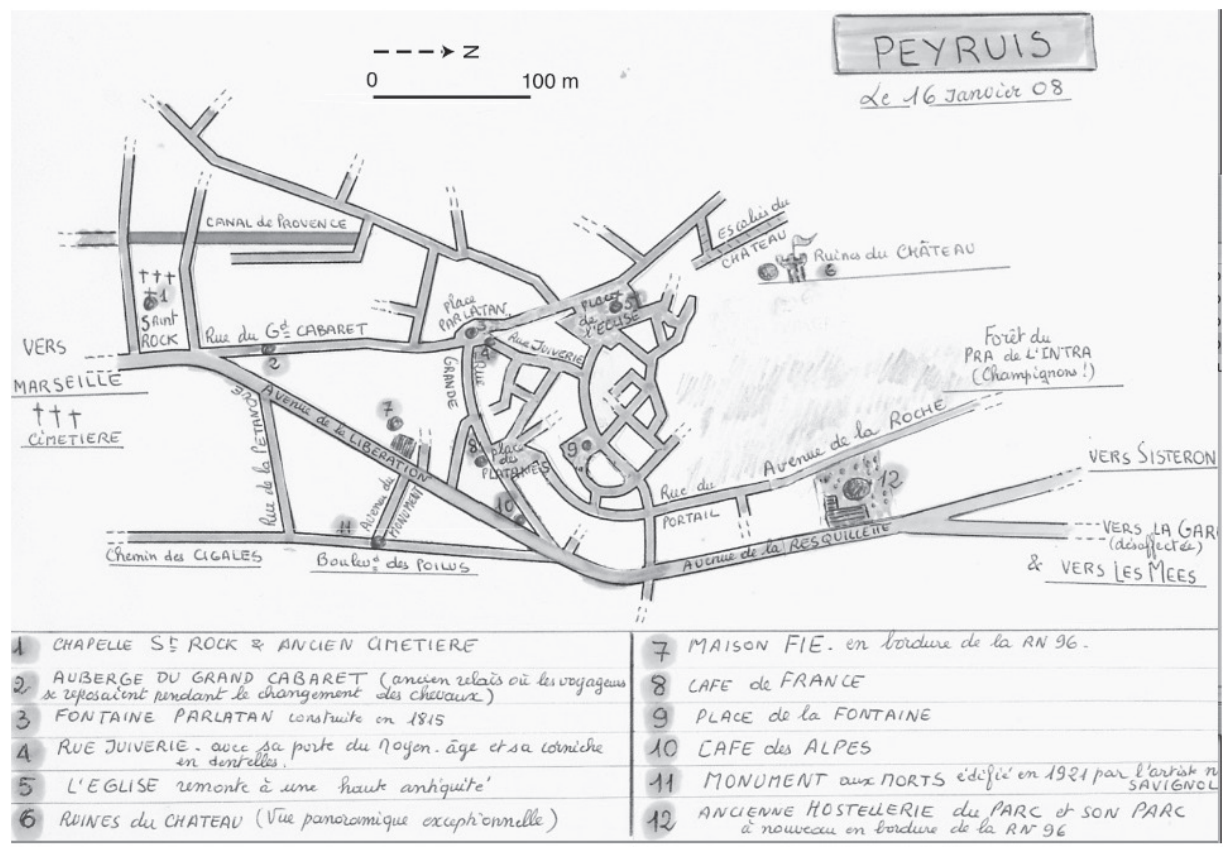

En el conjunto de los lugares famosos de su pueblo, además del castillo y de la fábrica de turrones Belon donde trabajó mi abuelo, las tres hermanas y su hermano escogieron destacar su escuela, la iglesia y el monumento a los caídos de la 1. ${ }^{\text {a }}$ Guerra Mundial. Entre los puntos de referencia del territorio de Peyruis, la escuela municipal jugaba un papel esencial ya que servía de interfaz entre la 
esfera de lo privado y la del público. Allí se mezcla el tiempo de la nación con los recuerdos personales, a veces vinculados con las privaciones de la guerra: «Es una escuela pública, en frente del ayuntamiento, de un lado las muchachas, del otro los muchachos. Las muchachas y los muchachos no se mezclaban. La maestra, en vez de dejarnos jugar durante el recreo, nos mandaba en su jardín para recoger las doríforas que invadían todo en ese tiempo» (Monique).

Sólo la iglesia, para esas jóvenes adolescentes de mediados de los años cuarenta, podía competir con la escuela municipal cuando se trataba de salir de casa y burlar la vigilancia de su madre. Aunque el edificio religioso en sí mismo no tenga nada de notable, su importancia simbólica y su papel social le confieren un sitio eminente en la corta lista de los lugares destacados de la pequeña comunidad (figura 5). Con sus ojos de niña, Josette lo encontraba «muy bonita». Para la hija menor, Mireille, la iglesia era un lugar mágico y misterioso donde, para Navidad, se elaboraba un Belén gigantesco con figuritas de barro: «Cuando iba al pueblo, había los lavaderos, las fuentes, las lavanderas. Esta pequeña carretera que subía. La iglesia me agradaba también. Era un poco oscura y me encantaba entrar en ella. Era un poco misterioso para mi. Todo me parecía bello, muy bonito. La iglesia de Peyruis es todavía bonita. Para Navidad, Había un gran Belén con grandes figuras. Lo admiraba durante mucho tiempo».

Figura 5: La iglesia de Peyruis (fotografía: Alain Musset, 2008)

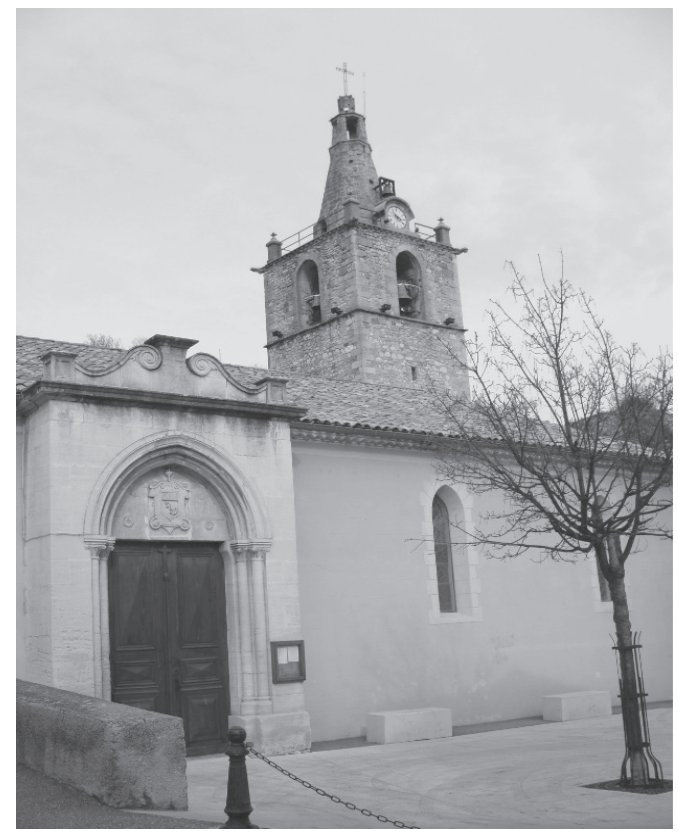

Para los ojos de la niña Mireille, todos los espacios de Peyruis tomaban proporciones descomunales, tal como el jardín de la casa del Parque donde estaba 
hospedada la familia: «Vivíamos en un parque que me parecía inmenso. Había una gran avenida bordada por sicomoros. Había boj, árboles, un gran abeto, un cerezo grande. Había también un albaricoquero sobre el cual iba a robar albaricoques aún no maduros, cuando era un poco más grande. Al fondo, había un lavadero y cerca del lavadero algunas escaleras que subían en los jardines. Allí, había dos estanques grandes. Había también una gran hilera de higueras y había el jardín de mi padre. Un pequeño jardín no demasiado cultivado.» A juicio de su hermano Jean (11 años en 1945), este parque era como una selva amazónica en donde solía vivir aventuras inspiradas de su gran héroe, Johnny Weissmuller, el Tarzan de las películas norteamericanas.

La interpenetración entre el espacio-tiempo social y el espacio-tiempo familiar aparece claramente en el momento de las fiestas religiosas que marcaban la vida de la comunidad. Por ejemplo, cada Lunes de Pentecostés, casi todos los habitantes del pueblo participaban a la peregrinación organizada por el cura de la parroquia hacia el santuario de Ganagobie, ubicado a unos cuantos kilómetros al sur de Peyruis. Esta peregrinación era para las familias de Peyruis la ocasión de ir de campo, dando a los niños la oportunidad de descubrir paisajes que ampliaban considerablemente sus territorios cotidianos.

De hecho, si se toman en cuenta las normas morales que regulaban el comportamiento de las muchachas en las familias modestas de Peyruis, el territorio íntimo de Monique y sus hermanas se reducía a poca cosa - y me refiero tanto al espacio realmente practicado como al tiempo que le correspondía, puesto que sus horarios de salida eran muy estrictos. Dicho territorio era tanto más estrecho cuanto que los trayectos se hacían generalmente a pie, raramente a bicicleta y excepcionalmente en tren - lo que limitaba las posibilidades de apertura hacia el exterior y el descubrimiento de nuevos horizontes. De hecho, la «cáscara» de la región definida por Moles (o sea «el conjunto de lugares donde puedo ir y volver en menos de un día») depende de los medios de comunicación a disposición de los individuos - de allí que su perímetro sea muy variable según la época estudiada, el tipo de sociedad que le corresponde y el lugar ocupado por el individuo en dicha sociedad.

Por esta misma razón, Josette recuerda con entusiasmo estos momentos privilegiados que hacían estallar la rutina de su vida cotidiana: «Salíamos a pie de Peyruis e íbamos hasta a Ganagobie cantando el Ave María y otros cantos religiosos a lo largo del camino. Era el único día en que papá se venía con nosotros para una comida campestre.$^{10}$ Solíamos escoger el mismo lugar, cerca de la fuente, para comer nuestros bocadillos. Hace unos años volvimos a Ganagobie y volvimos a esta fuente, volvimos al pequeño bosque que no había cambiado. Nos sentamos todos en el mismo lugar. Sentimos una emoción muy fuerte» (Josette).

10 Cabe destacar que mi abuelo era en esa época secretario de la célula del Partido Comunista de Peyruis - lo que no le impedía participar a una peregrinación organizada por el cura del pueblo. 


\section{LUGARES PÚBLICOS, HISTORIAS ÍNTIMAS}

Al trabajar sobre las memorias familiares y su relación con el espacio vivido, también se dibujan y se proyectan en un marco territorial las prácticas sociales de toda una comunidad. En un pequeño pueblo como lo era Peyruis en los años 1940, los acontecimientos familiares más importantes, en particular las bodas, suponían la participación de numerosos habitantes. La cohesión de la comunidad estaba garantizada por tradiciones como la de las «barras floridas» que permitía a las adolescentes preinscribirse en el calendario nupcial de la localidad, manifestando al mismo tiempo su cariño para la novia: «Las muchachas hacían barras decoradas a partir de ramas y palos. Los adornaban con follajes y flores. Los recién casados y todos los invitados tenían que saltar las barras. Tu madre lo hizo para su boda. Las muchachas las colocaban en otros lugares del pueblo, en las calles, para que todos los participantes de la misa las tuvieran que saltar. Al llegar a casa se ponían las barras delante de la puerta. Cuanto más barras había, más se honraba a la novia, más sus amigas le manifestaban su cariño» (Josette).

Espacio público por excelencia, la Plaza de los Cuatro Sicomoros era entonces el corazón político de Peyruis. Allí se asentaba el tianguis del domingo, allí se organizaban las reuniones electorales, allí la presidencia municipal solía recibir a las personalidades políticas que visitaban la región: «La plaza de los Cuatro Sicomoros, creo que todavía existe, pero no sé si quedan los sicomoros. Era la plaza del mercado. Era la plaza más importante. No se hacían reuniones en la plaza de la iglesia» (Josette). ${ }^{11}$ Monique y Josette se acuerdan perfectamente de los anuncios públicos hechos en las calles del pueblo por el vocero municipal: por este medio se avisaba a la población femenina que había llegado un vendedor de sombreros o de zapatos venido de Sisteron o Marsella.

A decir la verdad, los lugares «institucionales» de sociabilidad eran pocos sobre todo para las muchachas del pueblo. Al recordarlos, las tres hermanas han dibujado para mí el cuadro de una sociedad aún tradicional pese a la proximidad espacial del gran polo químico de Saint-Auban. Por ejemplo, Mireille hace hincapié en las fuentes y los lavaderos que salpicaban y, de cierta manera, estructuraban, el espacio urbano. Si bien casi todas las casas estaban conectadas a la red de agua potable, las mujeres aún lavaban la ropa a manos y el lavadero era para ellas un lugar no sólo de convivencia e intercambios sino también de conflictos.

Para facilitar los encuentros, los intercambios y la difusión de la información, Peyruis contaba con dos lugares fundamentales: el Café de France y el Bar del río Durance (también conocido como Casa de Rivarel), «dónde solíamos ir a bailar los domingos. Es un gran café donde había una terraza. El verano, se bailaba en la terraza, el invierno en la sala» (Monique). No es una casualidad si estos dos lugares ocupaban un lugar fundamental en la geografía personal de Monique ya que el baile era el principal entretenimiento de las adolescentes de ese tiempo. Aun más, era casi el único momento y lugar para ellas de encontrar a un novio. En este caso, la intimidad de los recuerdos se inscribe por necesidad

11 En 2009, solo quedaban tres sicomoros en la Plaza. 
en la publicidad de los lugares. De manera lógica (¡casi determinista!) Monique encontró a Richard ${ }^{12}$ (mi padre), venido de Saint-Auban para participar en un torneo de baloncesto, en un baile (su primero) organizado en el Café de France. Esta pequeña cantina ubicada en la Plaza de los Sicomoros sigue siendo un lugar donde se dan conciertos (figura 6).

Figura 6. Un pequeño lugar de memoria y un gran lugar de sociabilidad para muchas familias de Peyruis: El café de France (fotografía: Alain Musset, 2010)

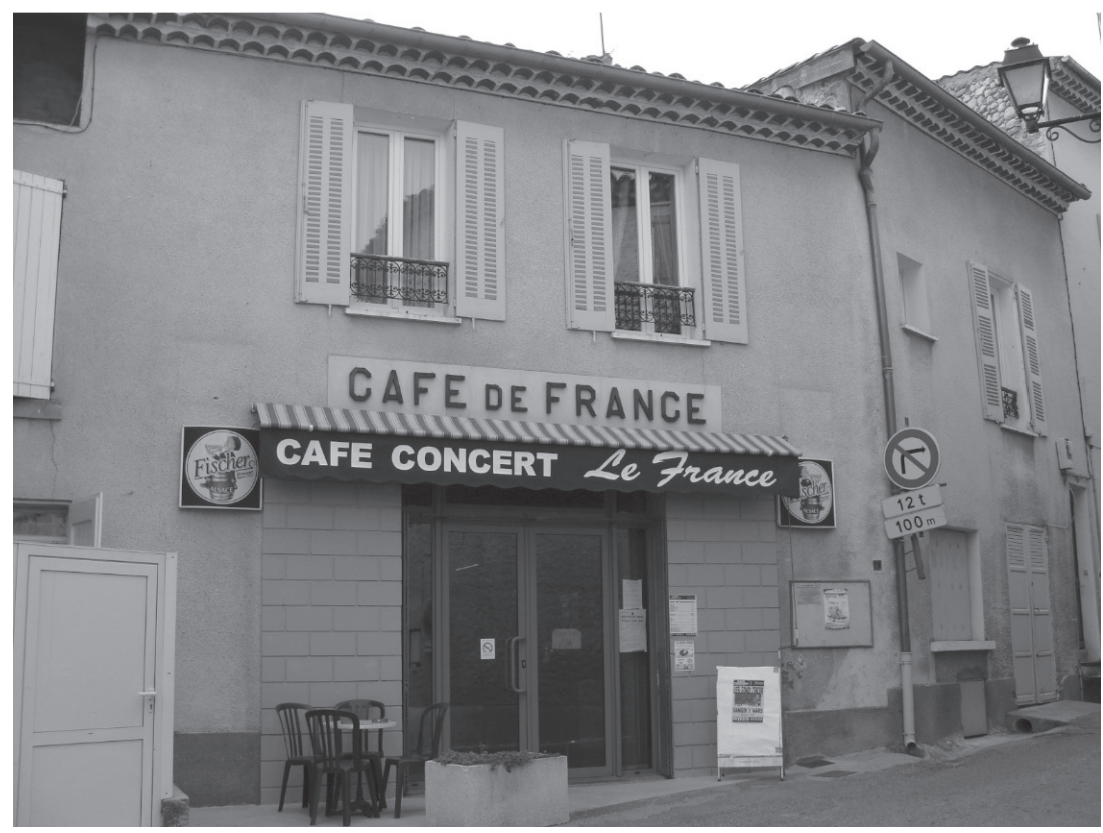

Su romance ha sido inmediatamente controlado ya que una joven quinceañera de mediados de los años cuarenta no podía independizarse tan fácilmente de su familia. Para su primera cita, Josette acompañaba a su hermana para evitar los malentendidos y los chismes: «El domingo siguiente, Monique tenía cita con Richard sobre el puente de los Mées. Salimos a pié. La acompañé y asistí a su primera cita. Y luego fuimos al cine». En este lugar público se besaron por primera vez, burlando así la vigilancia de su carabina: «Nos dimos nuestro primer beso en el cine de los Mées. Era una película con Madeleine Sologne y Jean Marais, El Eterno Retorno» (Monique).

La relación entre la intimidad de estos momentos y la publicidad de su escenario muestra hasta qué punto la geografía de los individuos no solamente se inscribe en un espacio social sino que no cesa de interferir con él para darle un

12 Richard Musset, nacido el 22 de octubre de 1926 en Argel. Se mudó de Marsella a SaintAuban en 1942, luego de la invasión de la Zona Libre del sur de Francia por el ejército alemán. Falleció en 2012. 
sentido. En efecto, a la altura de sus destinos personales, Richard y Monique hubieran podido nunca encontrarse o encontrarse fuera de Peyruis - y en Peyruis en otro lugar que en el Café de France. Sin embargo, su geografía amorosa fue orientada por las ideas y las prácticas de su grupo social de origen: cuando encontró a Monique, Richard era obrero en una planta química vecina. Y Monique era hija de un peón pagado para cargar y descargar toneles metálicos de 100 kilos. Ahora bien, tanto en la Provenza de los años 40 como en la París contemporánea, la clase obrera y la burguesía no comparten el mismo «mapa del amor».

Con todo, este mapa del amor puede ser dibujado, tal como lo hizo mi padre en enero del 2008 cuando tenía ya 82 años (figura 7). En este mapa mental, todo el espacio de Peyruis se organiza en función de la geografía amorosa que compartió con Monique y que da un significado especial a cada uno de los lugares así recordados y apuntados. Los lugares así destacados son: «la casa de Moni» y su parque; el café de Francia («baile donde encontré a Monique»); el café Rivarel («cine»); el «lugar con suelo de hormigón dónde se bailaba», a orilla de la carretera nacional 96; «ruinas del castillo» dónde los novios iban a pasear; la iglesia (lugar de la boda). Vale la pena destacar que siete kilómetros separan Peyruis de Saint-Auban (residencia de los padres de Richard). Para ver a Monique todos los días, después de su día de trabajo, Richard debía cruzar esta distancia a pie (a veces con bicicleta).

Figura 7. Los lugares destacados de Peyruis, según Monique et Richard (enero de 2008)

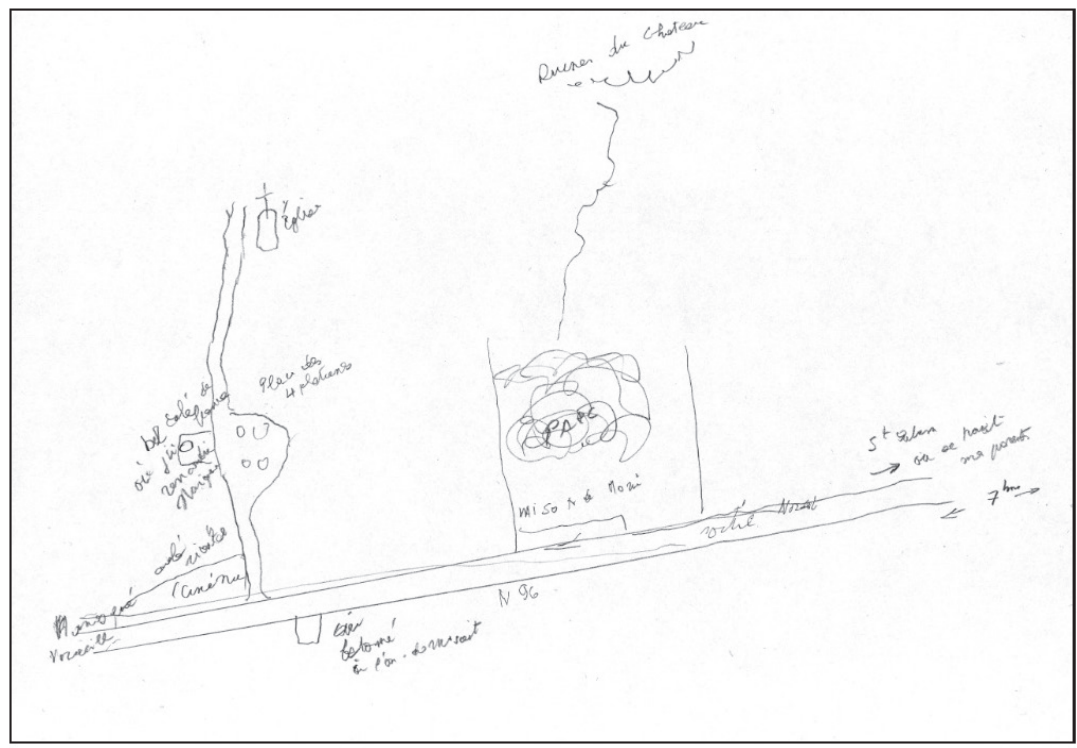

En este contexto, se entiende mejor porque el baile del Café de France era uno de los pocos lugares (y uno de los pocos momentos) donde y cuando Ri- 
chard y Monique tenían la oportunidad de encontrarse. Al mismo tiempo lugar público abierto a todos y lugar de memoria reservado sólo a los actores y espectadores de una historia particular, es el perfecto ejemplo de estos «pequeños lugares destacados» de las memorias familiares que se construyen al cruce de caminos entre el tiempo individual y el tiempo colectivo.

\section{CONCLUSIÓN}

Para la tercera generación de familia Vernet (de la que formo parte), Peyruis no es más que un nombre, una ciudad un poco virtual. Hasta 2008 y mi regreso al pueblo, en el marco de este estudio sobre las memorias familiares, me hubiera sido imposible siquiera volver a encontrar la antigua casa de mi tía y de mi abuela. De manera bastante simbólica, el único lugar que yo podía encontrar sin problema era el cementerio donde descansan mis abuelos. Se encuentra en el mismo lugar que servía de paseo vespertino a la familia Vernet en los años 40, como me lo recordó Josette al mencionar los lugares más importantes de su geografía personal: «Las tardes de verano, con papá y mama íbamos por la carretera hacia Saint Roch, hacia el cementerio donde están ahora sepultados. A lo largo de la carretera, había sicomoros y papá intentaba coger chicharras. Ir a pasear con papá y mamá, era maravilloso». No es de casualidad si, en mis propios recuerdos, sólo el cementerio lograse surgir de estos territorios familiares caídos en el olvido: allí, cada año, para el día de los muertos, solíamos traer flores para honrar la memoria de los desaparecidos.

Por esta razón me parece tan importante cuestionar el concepto de «lugares de memoria» o de «lugares destacados» a partir de una geografía del «yo» que favorezca los cambios de escala (geográfica y temporal) en el marco de una memoria colectiva. En efecto, la percepción íntima (individual o familiar) de los territorios no debe ser separada de la escenificación de los lugares por grupos sociales (con tamaño y geometría variables) en búsqueda de reconocimiento e identidad. A escala muy fina y en un tiempo muy corto, estos «pequeños lugares de memoria», basados en los recuerdos personales, estructuran y articulan nuestros espacios de vida dándoles un sentido y un significado. Es una dimensión del espacio geográfico, accesible a todos, que es preciso tomar en cuenta si se quiere entender cómo los individuos se integran (o no) a una comunidad y como se apropian, de manera transitoria y simbólica, parte de sus territorios.

Por supuesto, grupos distintos y de todo índole pueden ocupar de manera simultanea los mismos lugares - pero no les dan el mismo valor ni el mismo significado ya que su apropiación simbólica del espacio no se basa en la misma experiencia histórica ni en el mismo proceso de interacción social. Sería al respecto de sumo interés, dibujar una microgeografía de los lugares cotidianos basada en el punto de vista de varias familias que compartieron el mismo lugar de vida en el mismo momento - pero que no compartían el mismo nivel económico, las mismas preocupaciones diarias, la misma cultura política, o el mismo desempeño social. 
Pero cuando desaparecen los actores de esas pequeñas historias familiares, hasta los lugares más famosos en su momento pierden parte de su sentido (o más bien el sentido que les correspondía en el marco de esta «historia aún caliente» ideada por Fernand Braudel), sobre todo cuando las huellas físicas del pasado han sido arrastradas por el paso del tiempo. Es así como hoy en día la terraza donde, en los años 40 y 50, los jóvenes de Peyruis solían ir a bailar en busca de su primer amor ha sido convertido en un estacionamiento público - espacio anónimo e impersonal que ya no puede ubicarse en la memoria de la comunidad (figura 8).

Figura 8. El antiguo baile Rivarel de Peyruis convertido en estacionamiento público (fotografía: Alain Musset, 2010)

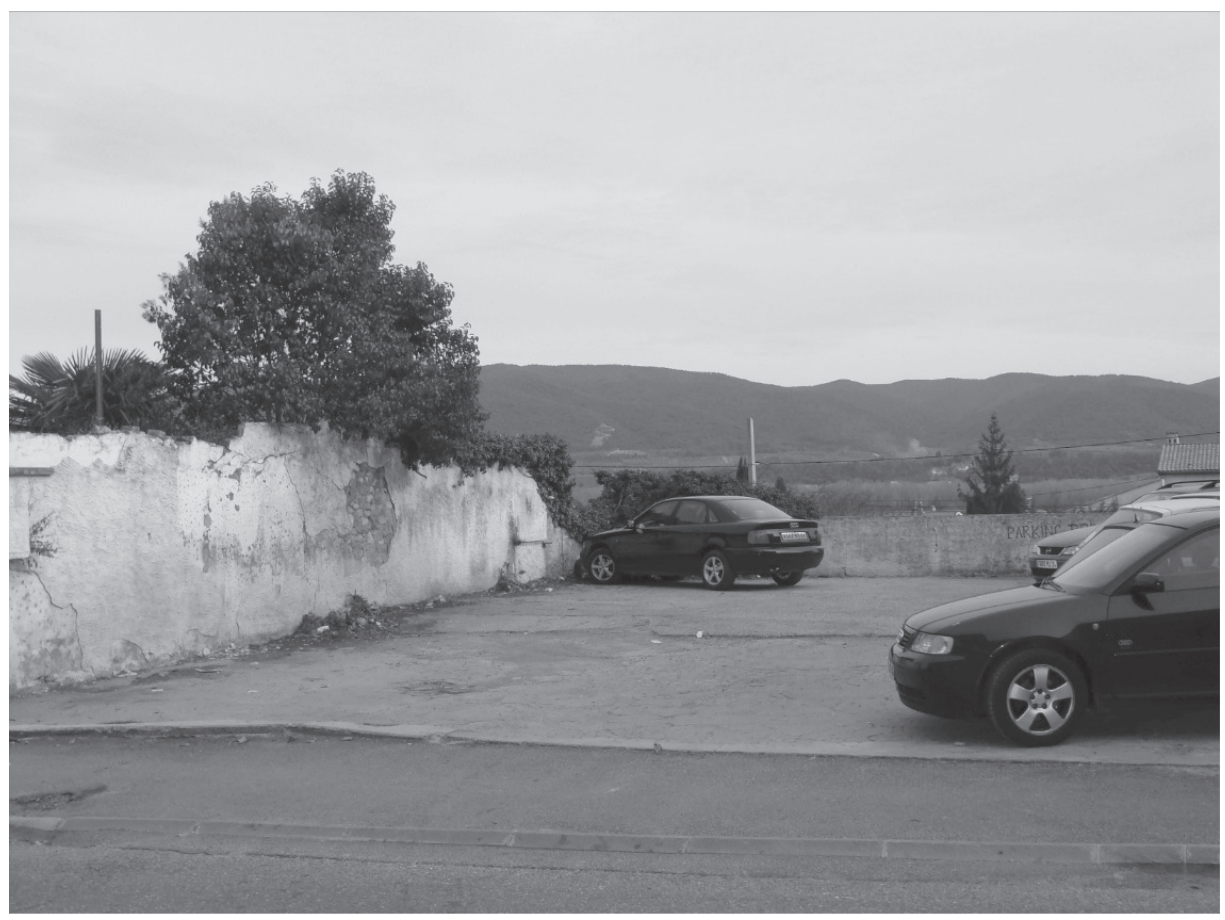

Éste es un buen ejemplo de esos pequeños lugares de memoria que no duran más que una vida humana pero que conforman la realidad (subjetiva, equívoca y polisémica) de nuestra relación personal y social con el mundo que nos rodea, tal como lo expresó Owain Jones en su tiempo al recordar por medio de una fotografía antigua, tomada por su propio hermano mayor, la pequeña finca en donde pasó su niñez y juventud: «Es la finca donde crecí. Esto también, tal como el Lamby, ha desaparecido, la finca, el patio, la granja, debajo de las urbanizaciones de East Cardiff a fines de los años 70» (Jones, 2007: 217). 
No obstante, cabe resaltar una extraña paradoja: al escribir la historia de esos territorios triviales relacionados con el pasado de mi propia familia, estoy cambiando las reglas del juego. Espacios cuyo destino era quedarse en el olvido o por lo menos cambiar de sentido, en el marco de nuevas interacciones sociales desarrolladas por otros grupos y otras familias, de aquí en adelante permanecerán como el escenario particular de un encuentro destacado y mediatizado no solamente por el recuerdo de un hijo sino también por el trabajo del historiador.

\section{BIBLIOGRAFÍA}

AUGÉ, M. (1998): Les formes de l'oubli. Paris, Payot-Rivages.

BÉDARD, M. (2002a): «Une typologie du haut-lieu, ou la quadrature d'un géosymbole», Cahiers de Géographie du Québec, volume 46, n²127, pp. 49-74.

http://www.cgq.ulaval.ca/textes/vol_46/no127/Bedard.pdf

BEDARD, M. (2002b): «De l'être-ensemble à l'être-au-monde. Le rôle du haut-lieu», Ethnologies Musées / Museums, Volume 24, numéro 2, pp. 229-241.

http://www.erudit.org/revue/ethno/2002/v24/n2/006649ar.html

BONNEMAISON, J. (1996): Les fondements géographiques d'une identité - l'archipel de Vanuatu : essai de géographie culturelle. Paris, ORSTOM.

BRAUDEL, F. (1990): La Méditerranée au temps de Philippe II (novena edición). Paris, le Livre de Poche.

CORAJOUD, M. (1990): «Regarder le haut-lieu de dos», en Michel Crépu et Richard Figuier (dir.), Hauts-lieux - Une quête de racines, de sacré, de symboles, Paris, Autrement, Mutations, 115, pp. 39-41.

DEBARBIEUX, B. (1995): «Imagination et imaginaire géographiques», en A. Bailly, R. Ferras, D. Pumain (dir.), Encyclopédie de géographie, Paris, Economica, pp. 875-888.

DI MÉO, Guy, La géographie en fêtes, Paris, Ophrys, 2001.

DAVIDSON, J., L. BONDI y M. SMITH (Ed.) (2007): Emotional Geographies, Aldershot, Ashgate.

HALBWACHS, M. (1967-1950): La mémoire collective, Paris, Les Presses universitaires de France, 1967, Deuxième édition revue et augmentée.

http://classiques.uqac.ca/classiques/Halbwachs_maurice/memoire_collective/memoire_ collective_tdm.html

JONES, O, (2007): «An Ecology of Emotion, Memory, Self and Landscape», en J. Davidson, L. Bondi y M. Smith (Ed.), Emotional Geographies, Aldershot, Ashgate, pp. 205-218.

LA SOUDIÈRE, M. (1991): «Les hauts-lieux... mais les autres?», en A. Micoud (dir.), Des Hauts-lieux - La construction sociale de l'exemplarité, Paris, CNRS, Centre régional de publication de Lyon, p. 17-31.

LÉVI, G. (2001): «Le passé lointain. Sur l'usage politique de l'histoire», en F. Hartog et J. Revel (dir.), Les usages politiques du Passé, Paris, EHESS, pp. 25-37.

MOLES, A. (1995): «Vers une psycho-géographie», en A. Bailly, R. Ferras, D. Pumain (dir.), Encyclopédie de géographie, Paris, Economica, pp. 159-187.

MICOUD, A. (1991): «La production symbolique des lieux exemplaires», en A. Micoud (dir.), Des Hauts lieux - La construction sociale de l'exemplarité, Paris, CNRS, Centre régional de publication de Lyon, pp. 7-15. 
MOUÏREN, J. (1997): Peyruis à travers le temps, Châteaux-Arnoux, Association Vivre à Peyruis.

NORA, P. (dir), (1997): Les lieux de mémoire, Paris, Gallimard, Quarto.

Piveteau, J.-L. (1995): «Le territoire est-il un lieu de mémoire ?», L'espace géographique, p. 113-123.

RICOEUR P. (2000): La Mémoire, l'histoire, l'oubli. Paris, Ed. du Seuil.

VERNET, J. (2003): Il était une fois... Souvenirs racontés par Jean R . P. Vernet. Aubignosc, Documento fotocopiado, $143 \mathrm{p}$.

VOLVEY, A., Y. CALBÉRAC y M. HOUSSAY-HOLZSCHUCH (2012): «Terrains de je. (Du) sujet (au) géographique», en Annales de Géographie, n 687-688, Septiembre-Diciembre de 2012, pp. 441-461. 
